Revista Destaques Acadêmicos, Lajeado, v. 9, n. 4, 2017. ISSN 2176-3070 DOI: http://dx.doi.org/10.22410/issn.2176-3070.v9i4a2017.1654 www.univates.br/revistas

\title{
APLICAÇÃO DA COMPOSTAGEM E DA VERMICOMPOSTAGEM EM SOLO CONTAMINADO COM ÓLEO LUBRIFICANTE USADO
}

\author{
Magali Primaz ${ }^{1}$, Ytan Andreine Schweizer², Eduardo Miranda Ethur ${ }^{3}$, \\ Cristiano Giovanella ${ }^{4}$, Lucélia Hoehne ${ }^{5}$
}

Resumo: O óleo lubrificante usado é considerado pela ABNT NBR 10.004:2004 um resíduo perigoso. Quando é destinado inadequadamente pode provocar graves problemas no solo, no ar e na água, pois possui elevados níveis de hidrocarbonetos e de metais em sua composição. Segundo a Resolução CONAMA n ${ }^{\circ} 362 / 2005$, o rerrefino é o destino adequado a este resíduo. A compostagem e a vermicompostagem são alternativas viáveis para o reaproveitamento de solos contaminados com óleo lubrificante. Estes processos aceleram a decomposição da matéria orgânica dos resíduos por meio da ação de micro-organismos e de minhocas, obtendo um material mais estável e com qualidade superior ao da matéria-prima inicial. Perante isso, o objetivo deste trabalho foi utilizar a compostagem e a vermicultura como técnica de recuperação de um solo contaminado com óleo lubrificante usado. Para isso, foram analisados parâmetros tais como $\mathrm{pH}$, nitrogênio total, fósforo, potássio, umidade e Hidrocarboneto Total de Petróleo (HTP), antes e depois do processo, afim de verificar a degradação dos compostos orgânicos do resíduo e o aumento dos nutrientes no solo. Como resultados pode-se verificar que houve aumento nos teores de fósforo, potássio e umidade no composto e no vermicomposto final, melhorando a qualidade do solo, consolidando a concepção de ser usado como fertilizante.

Palavras-chave: Hidrocarbonetos Policíclicos Aromáticos. Vermicultura. Fertilizante.

1 Graduada em Química Industrial da UNIVATES -mprimaz@universo.univates.br

2 Graduando em Engenharia Química da UNIVAES - ytan.schweizer@universo.univates.br

3 Doutor em Química pela UFSM - eduardome@univates.br

4 Mestrado em Ambiente e Desenvolvimento pela UNIVATES - crgiovanella@univates.br

5 Doutora em Química pela UNIVATES - luceliah@univates.br 


\section{INTRODUÇÃO}

Segundo a Associação Brasileira de Normas Técnicas - ABNT, A NBR 10.004 classifica o óleo lubrificante usado como um resíduo perigoso (ABNT, 2004), pois possui características agressivas ao meio ambiente e maléfico à saúde, além de não ser totalmente consumido durante a sua vida útil (CANCHUMANI, 2013; SILVA et al., 2014).

A contaminação com este resíduo é comum, devido ao descarte incorreto e vazamentos, e por ser um contaminante recalcitrante, promove grande impacto ao meio ambiente. Outro aspecto prejudicial ao meio ambiente é a maneira inadequada com que se gerencia este contaminante, sendo muitas vezes destinado em aterros juntamente com o lixo comum ou ainda queimado de forma incorreta (KUCZENSKI et al., 2014).

Conforme Resolução n 362 de 23 de junho de 2005 do Conselho Nacional do Meio Ambiente - CONAMA, o óleo lubrificante usado não pode ser descartado em aterros sanitários. A Resolução estabelece que o destino correto para esse resíduo perigoso é a reciclagem, com a coleta realizada por empresas autorizadas e o envio para o rerrefino (BRASIL, 2005).

Quando lançado diretamente no ambiente ou queimado, causa grave problema de poluição no solo, na água e no ar. No solo, se infiltra juntamente com a água da chuva contaminando-o, e quando atinge os lençóis freáticos, polui também as águas subterrâneas (SILVEIRA; CALAND; MOURA, 2006). Nas redes de drenagem de águas residuais contaminam os meios hídricos e provocam também estragos nas estações de tratamento.

Os óleos lubrificantes possuem elevados níveis de hidrocarbonetos (BORIN; POPPI, 2004) e de metais (HSU, 2005). Os Hidrocarbonetos Policíclicos Aromáticos (HPA's) são compostos químicos formados unicamente de átomos de carbono e hidrogênio, na forma de dois ou mais anéis aromáticos (POTIN et al., 2004), originados da combustão incompleta da matéria orgânica (BAMFORTH; SINGLETON, 2005).

Os HPA's se apresentam na forma lipossolúvel na membrana celular e a exposição aos seres humanos pode acontecer por diferentes maneiras, como inalação oral e absorção pela pele (NETTO et al., 2000).

A ação realizada pelos HPA's é ativada durante o seu processo metabólico, ocorrendo formação de compostos hidrossolúveis. No metabolismo de eliminação ocorre a formação de epóxidos, e de compostos polihidroxilados, mais solúveis em água, visando à eliminação na urina. Um destes intermediários pode reagir com a guanina do ácido desoxirribonucléico (DNA) e formar um aduto, originando um processo de tumoração (IARC, 2006).

Mais de 100 HPA's são reconhecidos pela International Union of Pure and Applied Chemistry (IUPAC), mas somente 16 são considerados em função de sua importância industrial, ambiental e toxicológica. 
Em 1922 foram obtidos os primeiros dados referentes aos riscos ocupacionais e ambientais dos HPA's, pela demonstração que extratos orgânicos de fuligem eram carcinogênicos em animais. Em 1931, o estudo com os HPA's teve início com o isolamento do benzo(a)pireno $(\mathrm{BaP})$ a partir do carvão. $\mathrm{O}$ $\mathrm{BaP}$ também foi identificado em fuligem doméstica e em material particulado ambiental, e em 1970, ele foi caracterizado como um agente cancerígeno de classificação mundial em ambientes respiráveis e como constituinte de aerossóis urbanos (COSTA, 2001). Tais fatores foram fundamentais para o desenvolvimento de técnicas com capacidade de degradar estes compostos.

A atividade antropogênica é a maior responsável pela contaminação do solo por estes resíduos oleosos. Um dos mais preocupantes problemas destes compostos é que são muito persistentes no ambiente (SHU et al., 2003). As indústrias geram HPA's nos processos de fabricação de corantes, fibras sintéticas, preservantes de madeira, na produção de carvão vegetal, na extração e gaseificação do carvão mineral e entre outros processos e utilização do petróleo e de seus derivados (BAMFORTH; SINGLETON, 2005).

A compostagem é uma técnica de biodecomposição da matéria orgânica dependente de oxigênio em suas reações. Este tratamento é um processo biológico, pois envolve vários grupos de microrganismos em sucessão que transformam o resíduo em decomposição e que afetam e são afetados pelos fatores físicos e bioquímicos envolvidos durante o processo. Esta técnica utiliza a ação de microrganismos mesófilos, que possuem atividade até a temperatura de $45{ }^{\circ} \mathrm{C}$, e os termófilos, que atuam na faixa superior a $45{ }^{\circ} \mathrm{C}$, podendo chegar até $60^{\circ} \mathrm{C}$. A ação da deterioração biológica utiliza o $\mathrm{O}_{2}$ disponível para transformar o carbono do substrato orgânico para obter energia, liberando $\mathrm{CO}_{2}$, água e gerando calor, que leva a um produto estável semelhante ao húmus de minhoca, chamado de composto orgânico (MASON; MILKE, 2005), conforme demonstrado na Reação 1.

$$
\text { Matéria orgânica }+\mathrm{O}_{2} \rightarrow \mathrm{CO}_{2}+\mathrm{H}_{2} \mathrm{O}+\text { energia (calor) + húmus }
$$

A vermicompostagem é uma técnica de aceleração de decomposição de matéria orgânica utilizada para acelerar a compostagem.

Os processos envolvidos na ação das minhocas sobre a matéria orgânica são mecânicos e biológicos. O revolvimento, a aeração do composto e a trituração das partículas orgânicas que passam pelo trato digestivo constituem um processo mecânico. O efeito bioquímico está presente na decomposição da matéria orgânica pelos microrganismos no intestino das minhocas, gerando resíduos mais ricos em nutrientes (GARG; YADAY, 2011).

Garg et al. (2012), em seu experimento, realizou o processo de vermicompostagem utilizando resíduos de indústrias de alimentos e, após 15 semanas, ocorreu o aumento de mais de $60 \%$ de nitrogênio $(\mathrm{N}), 36$ a $70 \%$ de potássio $(\mathrm{P})$ disponível, 39 a 95\% de sódio $(\mathrm{Na})$ e 44 a $74 \%$ de fósforo (K), além de queda no pH e aumento de 28 a 36\% de carbono orgânico total (COT) e de 61 
a $78 \%$ da relação carbono/nitrogênio $(\mathrm{C} / \mathrm{N})$. Observou-se neste estudo que a vermicompostagem pode ser considerada um adubo orgânico, pois transforma os resíduos poluentes de indústrias em compostos com características físicoquímicas essenciais para as plantas.

Para que o processo de vermicompostagem seja eficaz é muito importante à escolha da espécie de minhoca, pois no Brasil existem entre $240 \mathrm{e}$ 260 espécies, sendo que a mais utilizada pelos produtores de húmus é a Eisenia Andrei, pois tem melhor adaptação aos ambientes do processo (SCHIEDECK; GONÇALVES; SCHWENGBER, 2006; SCHIEDECK, 2010). Além disso, a Eisenia andrei é espécie mais utilizada para resíduos domiciliares, devido ao maior ganho de biomassa e reaproveitamento de resíduo (NADOLNY, 2009; SCHIEDECK, 2010).

Uma das vantagens deste processo é a produção do húmus, pois possui características bioenergéticas importantes (FERNANDES et al., 2009). O húmus é constituído de substâncias húmicas $(\mathrm{SH})$, que são misturas heterogênicas de compostos orgânicos unidos por interações intermoleculares fracas de caráter hidrofóbico e por ligações de hidrogênio. São fracionadas em ácidos húmicos (AHs), ácidos fúlvicos (AFs) e huminas (HUM) (BALDOTTO et al., 2013). Apresentam alto caráter aromático e variadas porções fenólicas e carboxílicas (MATILAINEN et al., 2011; VALENCIA et al., 2013).

Os AHs possuem coloração escura, apresentam alto teor de anéis aromáticos e grupos funcionais hidrofílicos contendo oxigênio (PIMENTA et al., 2009).

A HUM é insolúvel em meio alcalino e em meio ácido e possui reduzida capacidade de reação. Possui elevada hidrofobicidade e intensa interação com os componentes inorgânicos, podendo ainda conter compostos lipídicos, estruturas de carboidratos e aromáticos em diferentes proporções (RICE, 2001).

Segundo Silva (2007), os AFs são solúveis em meio alcalino e em meio ácido, constituídos por polissacarídeos, aminoácidos e compostos fenólicos. São mais reativos do que os AHs e a HUM, pois possuem maior quantidade de grupos carboxílicos e fenólicos.

Para verificar o comportamento de sobrevivência das minhocas com o solo contaminado, é aplicado o teste 'Avoidance', que determina a biodisponibilidade de substâncias químicas ou de contaminantes no solo, onde os organismos manifestam um comportamento de fuga, utilizado como indicador é aplicado. Apesar de ser um método rápido e simples, é pouco explorado no Brasil. O ensaio é padronizado como o Soil quality - Avoidance test for testing the quality of soils and effcts of chemical on behavior. Part1: Test with earthworms faz menção à utilização de minhocas das espécies Eisenia fétida e Eisenia andrei como organismos teste. O princípio deste teste é expor as minhocas simultaneamente a amostras de solo não contaminado (controle) e contaminado, em que as duas amostras são colocadas no mesmo recipiente, em 
partes distintas, e separadas por uma divisória, formando dois compartimentos. Após, a divisória é retirada, formando uma linha onde 10 minhocas que são colocadas na superfície, e após 8 horas, é verificado o número de minhocas em cada compartimento do recipiente. A amostra é considerada tóxica quando forem encontrados mais de $80 \%$ do total das minhocas expostas na amostra do solo controle (ISO 17512-1, 2007).

Dessa forma, o objetivo deste trabalho foi aplicar as técnicas de compostagem e de vermicompostagem em um solo contaminado com óleo lubrificante usado, utilizando minhocas da espécie Eisenia andrei, para verificar a degradação dos compostos orgânicos do resíduo.

\section{METODOLOGIA}

\section{Origem do óleo}

A amostra do óleo lubrificante usado é oriunda da troca de óleo de motocicletas realizadas durante o mês de abril de 2016. Este resíduo é armazenado em tambores metálicos de $200 \mathrm{~L}$ e foi recolhido em um frasco apropriado para posterior teste de fuga das minhocas.

\section{Teste de fuga das minhocas:}

Antes do início do processo da vermicompostagem, foi realizado o teste de fuga com as minhocas, onde elas foram expostas por $24 \mathrm{~h}$ a diferentes concentrações de óleo lubrificante usado, a fim de encontrar a quantidade onde melhor se adaptassem.

O ensaio foi baseado de acordo com o teste Avoidance test for testing the quality of soils and effcts of chemical on behavior. Part1: Test with earthworms (ISO 17512-1, 2007) e consistiu em dividir o recipiente plástico ao meio, onde de um lado foi colocado o solo (controle) e do outro o solo contendo diferentes adições de óleo lubrificante. Então, 10 minhocas foram acondicionadas ao meio dessa divisão, e após $24 \mathrm{~h}$, foi verificada a condição em que as minhocas permaneceram no solo contaminado. Dessa forma, foram adicionados: 1,0; 5,0; 10,$0 ; 50,0 ; 100,0 ; 200,0$ e $300,0 \mathrm{ml}$ do óleo em $1000,0 \mathrm{~g}$ de solo e inoculadas 10 minhocas respectivamente em cada recipiente.

\section{Preparo da Vermicompostagem:}

O solo utilizado na compostagem e na vermicompostagem foi coletado próximo a um posto de combustível em Lajeado/RS, no bairro Conventos, licenciado pela Fundação Estadual de Proteção Ambiental Henrique Luiz Roessler - FEPAM, e sem vestígio de contaminação. 
A avaliação dos processos de degradação dos compostos orgânicos foi realizada usando o solo distribuído em recipientes plásticos padronizados em formato retangular com dimensões $10 \times 10 \times 17 \mathrm{~cm}$.

Para o processo da compostagem, em três recipientes foram adicionados $1000,0 \mathrm{~g}$ de solo, 100,0 mL de óleo lubrificante usado e resíduo orgânico triturado.

Para o processo de vermicompostagem, nos outros três recipientes foram adicionados 1000,0 g de solo, 100,0 mL de óleo lubrificante usado. Neste ensaio foram inoculadas 20 minhocas com resíduo orgânico triturado como fonte de alimento. Todos os recipientes foram identificados e cobertos com tampa perfurada para evitar fugas, proteger contra predadores, temperatura e umidade. Coletou-se o substrato antes e após os 60 dias do processo de compostagem e da vermicompostagem, a fim de avaliar os parâmetros físicoquímicos das amostras.

\section{Análises físico-químicas:}

As análises para determinação do $\mathrm{pH}$, umidade, fósforo por espectrofotometria na região do visível, potássio por fotometria de chama e Nitrogênio Kjeldahl Total (NKT) foram desenvolvidas através dos procedimentos analíticos do Instituto Adolfo Lufz (2008).

Carbono orgânico total, extrato húmico total, carbono e ácidos húmicos e fúlvicos foram seguidos pela Instrução Normativa SDA n ${ }^{\circ} 28$ de 27 de Julho de 2007 do Ministério da Agricultura, Pecuária e Abastecimento - MAPA (BRASIL, 2007).

O TPH total foi analisado pelo laboratório Innolab do Brasil Ltda, acreditado pela CGCRE/Inmetro, de acordo com a ABNT NBR ISO/IEC 17025 e credenciado pela FEPAM. A determinação das concentrações foi feita por cromatografia gasosa com detecção por ionização em chama (CG/FID), método ISO 16703:2004 (E); US EPA 8015 D:2003.

\section{RESULTADOS E DISCUSSÃO}

\section{Teste de fuga:}

Após o teste de fuga, verificou-se que a condição mais adequada para que as minhocas permanecessem no meio contaminado foi de 100,0 $\mathrm{mL}$ de óleo lubrificante usado em 1000,0 g de solo. Os solos com volumes de 200,0 e 300,0 $\mathrm{mL}$ de óleo não apresentavam mais características de um habitat normal para as minhocas e, após $24 \mathrm{~h}$, elas não sobreviveram. A Figura 1 evidencia os frascos plásticos onde os processos de compostagem (A) e da vermicompostagem (B) foram montados. 
Figura 1 - Recipientes montados com a compostagem e a vermicompostagem

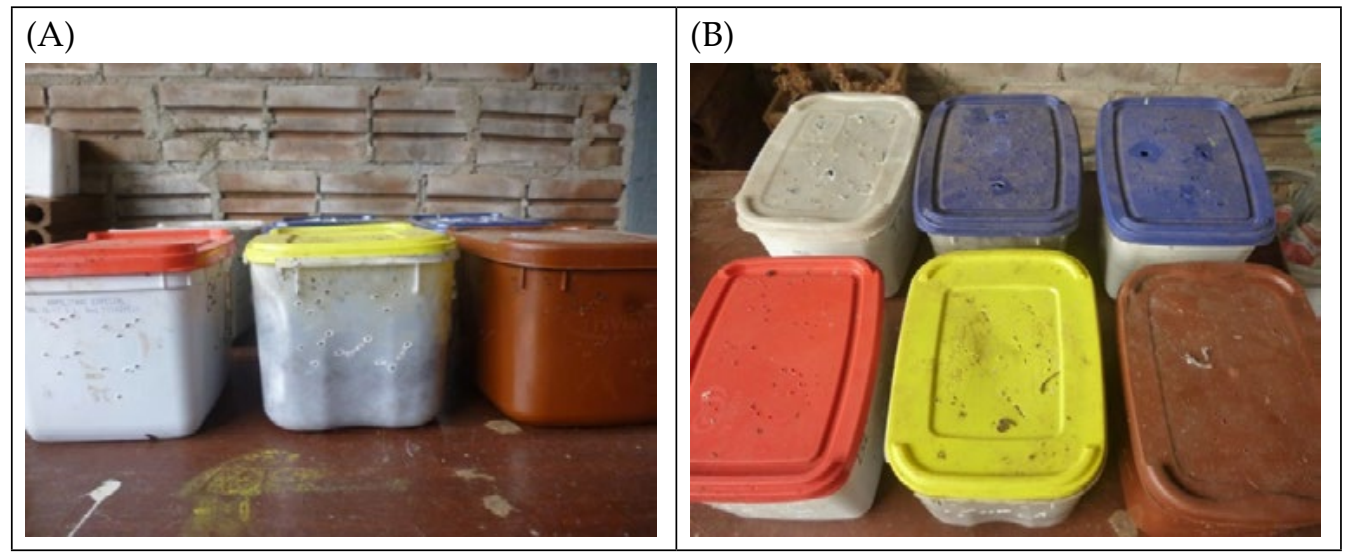

Fonte: Dos autores

A Figura 2 mostra as imagens do aspecto do solo inicial (A), do processo após a compostagem (B), após o processo da vermicompostagem (C) e das minhocas usadas (D).

Figura 1 - Imagens dos diferentes aspectos dos solos e das minhocas

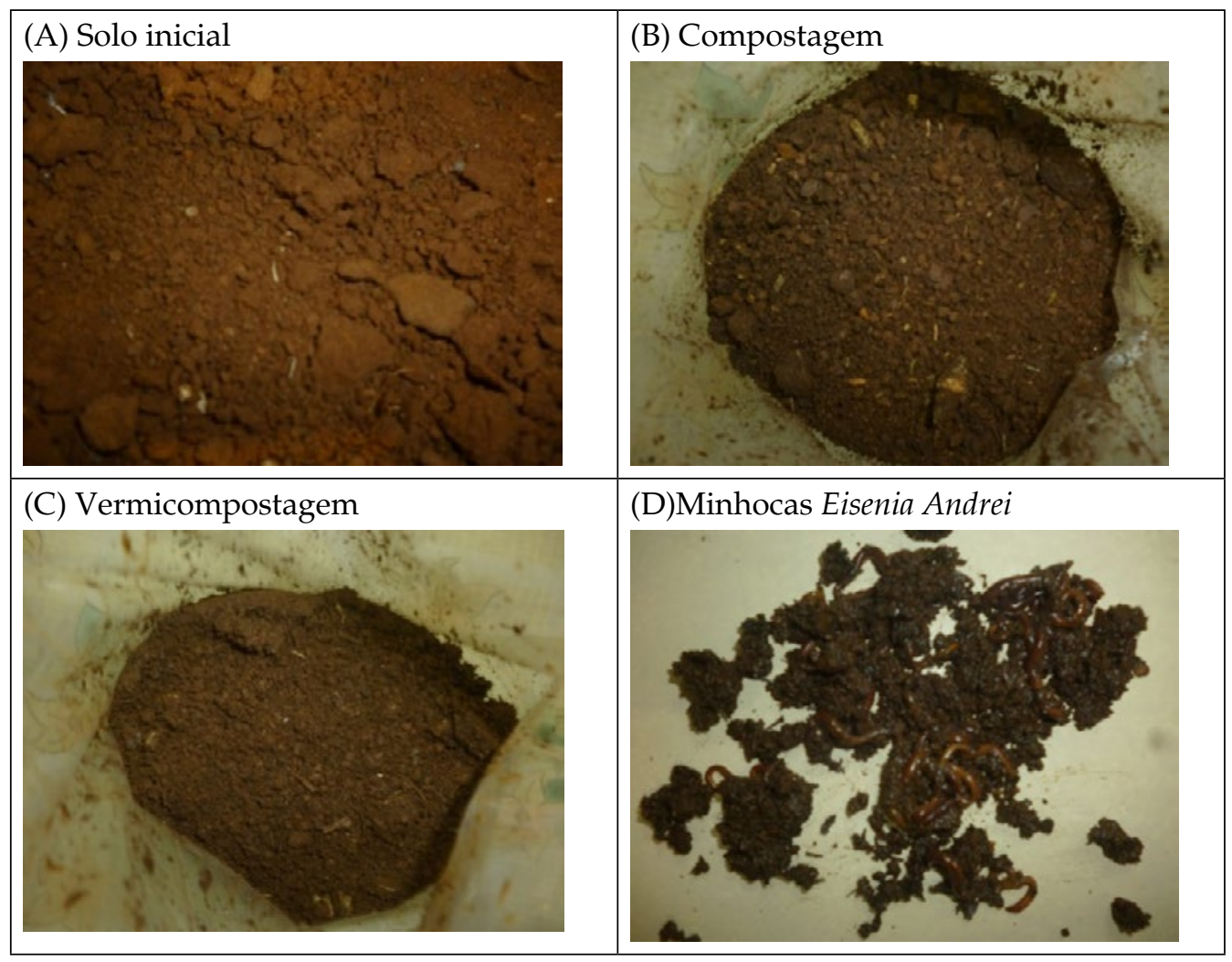

Fonte: Elaborado pelos autores. 
Pode-se observar que o solo, após a compostagem e a vermicompostagem, apresentou aspectos visuais típicos de um solo humificado, ou seja, com a coloração de cinza escura para preto, sendo que o óleo lubrificante usado pode ter contribuído na aparência, diferente do solo usado inicialmente.

Conforme Novotny et al. (2006), o húmus é caracterizado como uma substância amorfa e de cor preta. Na Tabela 1, estão relacionados os resultados das análises físico-químicas da mistura do óleo lubrificante usado com o solo antes de qualquer tratamento, após o processo da compostagem e da vermicompostagem.

Tabela 1 - Resultados das análises físico-químicas da mistura do óleo lubrificante usado com o solo antes do tratamento, após o processo da compostagem e da vermicompostagem

\begin{tabular}{l|c|c|c}
\hline Parâmetros & OLUB usado com o solo & Compostagem & Vermicompostagem \\
\hline Fósforo $(\mathrm{mg} / \mathrm{g})$ & $0,060 \pm 0,001$ & $0,105 \pm 0,022$ & $0,109 \pm 0,023$ \\
\hline Potássio $(\mathrm{mg} / \mathrm{g})$ & $0,235 \pm 0,020$ & $1,484 \pm 0,1$ & $1,520 \pm 0,1$ \\
\hline Nitrogênio total $(\%)$ & $0,489 \pm 0,006$ & $0,019 \pm 0,01$ & $0,521 \pm 0,01$ \\
\hline $\mathrm{pH}$ & $6,80 \pm 0,16$ & $6,56 \pm 0,01$ & $6,50 \pm 0,01$ \\
\hline Umidade $(\%)$ & $29,6 \pm 0,006$ & $31,7 \pm 0,4$ & $36,2 \pm 0,4$ \\
\hline TPH total $(\mathrm{mg} / \mathrm{Kg})$ & 800,000 & 5985,00 & 3128,00 \\
\hline
\end{tabular}

Legenda: OLUB: Óleo lubrificante.

Fonte: Dos autores

Segundo Teixeira et al. (2004), a faixa ideal de umidade para a ação dos microrganismos benéficos à compostagem é de $55 \%$ a $60 \%$, pois nesta faixa favorece o processo de decomposição. A umidade aumentou em ambos os processos, o que pode ter ocorrido devido a aeração dos microrganismos existentes, sendo que na vermicompostagem o aumento foi mais significativo, pois ocorre o revolvimento das minhocas. Cabe salientar que o processo durou 60 dias, ou seja, talvez com mais tempo de decomposição, poderia aumentar ainda mais a umidade.

Quanto ao parâmetro $\mathrm{pH}$, ambos os processos diminuíram o valor do parâmetro. Segundo Rodrigues et al. (2006), a faixa considerada ótima de $\mathrm{pH}$, onde ocorre o desenvolvimento dos micro-organismos, estimasse-se que seja entre 5,5 e 8,5, sendo que a maioria das enzimas encontram-se ativas nesta faixa.

Essa diminuição do $\mathrm{pH}$ pode ser justificada pela decomposição da matéria orgânica com a formação de ácidos orgânicos (KIEHL, 2004).

Quanto aos valores de $\mathrm{P}, \mathrm{K}$ e $\mathrm{N}$, na vermicompostagem ocorreu o aumento desses parâmetros, provavelmente devido ao processo de fixação 
desses elementos após digestão das minhocas, onde o solo é misturado com muco digestivo, o que ajuda na união de partículas, e a deposição fecal, que contém grandes concentrações de nutrientes que contribuem com o desenvolvimento do húmus e na fertilidade do solo (SHIPITALO \& BAYON 2004).

Já no processo de compostagem ocorreu a diminuição do $\mathrm{N}$ presente no substrato. Segundo Tiquia \& Tam (2000) e Raviv et al. (2004), estas perdas são causadas provavelmente pela volatilização de $\mathrm{NH}_{3}$. Já os teores de $\mathrm{P}$ e $\mathrm{K}$ aumentaram, devido à ação dos microrganismos envolvidos na compostagem, tornando o composto rico em nutrientes (VICENTINI, 2009).

Para justificar a elevação dos resultados de TPH total nas técnicas de compostagem e de vermicompostagem, conforme já demonstrados anteriormente na Tabela 1, foi necessário avaliar as $\mathrm{SH}$ que estão presentes nestes processos. Na Tabela 2 estão descritos os resultados das análises do COT, EHT, AHs e AFs.

Tabela 2 - Resultados físico-químicos do solo, da compostagem e da vermicompostagem

\begin{tabular}{l|c|c|c}
\hline \multicolumn{1}{c|}{ Parâmetros } & Solo inicial & Compostagem & Vermicompostagem \\
\hline Carbono orgânico total (\%) & $23,0 \pm 2,1$ & $15,7 \pm 0,2$ & $18,7 \pm 0,2$ \\
\hline Extrato húmico total (\%) & $22,7 \pm 4$ & $27,1 \pm 0,1$ & $32,2 \pm 0,1$ \\
\hline Ácidos húmicos (\%) & $13 \pm 1,5$ & $20 \pm 0,1$ & $16,2 \pm 0,1$ \\
\hline Ácidos fúlvicos (\%) & $9,76 \pm 1,5$ & $7,1 \pm 1,5$ & $16 \pm 0,1$ \\
\hline
\end{tabular}

Fonte: Dos autores.

Como pode ser observado, havia mais COT nos resultados do solo inicial, provavelmente devido à adição do óleo lubrificante usado, contendo vários compostos orgânicos, que ao passar pelos dois tratamentos teve suas concentrações reduzidas. $\mathrm{O}$ carbono orgânico pode ter sido volatilizado em forma de $\mathrm{CO}_{2}$.

Os teores de EHT e AHs aumentaram devido à degradação dos compostos orgânicos e pelo aumento da umidade graças à ação dos microrganismos e das minhocas. Dessa forma, é possível justificar em partes o aumento do TPH total em ambos os processos, pois como na técnica de cromatografia é avaliada a soma das massas dos compostos de uma determinada faixa, na verdade houve a decomposição destes, formando novo compostos com massas similares, induzindo a um aumento desses teores. Porém, para se comprovar, é necessária a realização de novas análises utilizando a técnica de cromatografia com detecção de massa/massa. 


\section{CONCLUSÃO}

Verificou-se neste estudo que foi possível aplicar o processo de compostagem e vermicompostagem em solo contaminado com óleo lubrificante usado, além de aumentar a concentração de $\mathrm{P}, \mathrm{K}$ e umidade dos compostos, sendo que os dois processos foram eficazes para a degradação dos HPAs em 60 dias. Assim, esses procedimentos podem ser usados para revitalização do solo contaminado. Cabe salientar que demais análises devem ser feitas a fim de qualificar os outros compostos orgânicos que não foram detectados neste trabalho. Futuros testes ainda serão feitos com mais tempo de compostagem e de vermicompostagem para garantir a degradação dos compostos orgânicos.

\section{REFERÊNCIAS}

\section{ASSOCIAÇÃO BRASILEIRA DE NORMAS TÉCNICAS - ABNT. NBR 10004:}

Resíduos Sólidos: Classificação. Rio de Janeiro: ABNT 2004. Disponível em: <http:/ / www.videverde.com.br/docs/NBR-n-10004-2004.pdf>. Acesso em: 28 ago. 2016.

BALDOTTO, M.A.; GOBO, A.A.R.; SALOMÃO, M.S.M.B.; REZENDE, C.E.; CAMARGO, P.B. Frações da matéria orgânica e propriedades redox de substâncias húmicas em sedimentos de oceanos profundos. Química Nova, n. 36, p. 1288 -1295, 2013.

BAMFORTH, S.; SINGLETON, I. Bioremediation of polycyclic aromatic hydrocarbons: current knowledge and future directions. Journal of Chemical Technology and Biotechnology, Sussex, v. 80, n. 7, p. 723-736, 2005.

BORIN, A.; POPPI, R. J. Multivariate quality control of lubricating oils using Fourier transform infrared spectroscopy. Journal Brazilian Chemical Society. São Paulo, v. 15, n. 4, p. 570-576, 2004.

BRASIL. Resolução 362 do Conselho Nacional do Meio Ambiente de 23 de junho de 2005. Regulamentação da Coleta, Transporte, Armazenamento e Destinação Adequada dos óleos lubrificantes usados e contaminados. Disponível em: <http:/ / www.mma.gov.br/port/conama/res/res05/res36205.xml>. Acesso em: $26 \mathrm{de}$ abr. 2016.

BRASIL. Instrução Normativa $\mathbf{n}^{\circ} \mathbf{2 8}$, de 27 de julho de 2007. Aprova os métodos analíticos oficiais para fertilizantes minerais, orgânicos, organominerais e corretivos, constantes do Anexo da IN. Diário Oficial da União de 31 de julho de 2007, Seção 1. Brasília, DF. Disponível em: http:/ / sistemasweb.agricultura.gov.br/ arquivosislegis/anexos/arquivos/1204363.PDF. Acesso em: 09 de nov. 2016.

CANCHUMANI, G.A.L. Óleos Lubrificantes Usados: um estudo de caso de avaliação de ciclo de vida do sistema de rerrefino no Brasil. 2013. Tese (Doutorado em Planejamento Energético) - Universidade Federal do Rio de Janeiro, Rio de Janeiro, 2013. 
COSTA, A. F. Avaliação da contaminação humana por hidrocarbonetos policíclicos aromáticos (PAHs): 1- hidroxipireno urinário. Dissertação. Centro de estudos de Saúde do trabalhador e Ecologia Humana da Fundação Oswaldo Cruz, Escola Nacional de Saúde Pública. Rio de Janeiro, 2001.

FERNANDES, J. D.; MONTEIRO, F. A. F.; SANTOS, S. A. dos.; VASCONCELLOS, A.; SANTOS, J. L. dos.; AUGUSTO, T. Utilização de Diferentes Substratos como Iscas na Captura de Minhocas, Revista Brasileira De Agroecologia, v. 4, n. 2, p. 2388-2391, nov. 2009.

GARG, V. K.; SUTHAR, S.; YADAV, A. Management of food industry waste employing vermicomposting technology. Bioresource Technology, Ed. 126. p. 437-443, 2012.

GARG, V. K.; YADAY, A. Vermicomposting: An effective tool for the management of invasive weed Parthenium hysterophorus. Bioresource Technology, v. 102, n. 10, p. 5891$5895,2011$.

HSU, S. M. Boundary lubricating films: formation and lubrication mechanism. Tribology International, v. 38, n. 3, p. 305-312, 2005.

INTERNACIONAL AGENCY FOR RESEARCH ON CANCER - IARC. Monographas on the evalution of carcinogenic risk of chemicals to humans. Polycyclic Aromatic Hydrocarbons. 2006. Disponível em: <http:/ / monographs.iarc.fr/ENG/Meetings/92_ pahs.pdf>. Acesso em: 28 ago. 2016.

INTERNATIONAL ORGANIZATION FOR STANDARDIZATION - ISO. Soil quality - Avoidance test for testing the quality of soils and effects of chemicals on behaviour - Part 1: Test with earthworms (Eisenia fétida and Eisenia andrei). ISO 17512-1. Geneva, Switzerland, 2007. Disponível em: <http:/ / http:/ / ainfo.cnptia.embrapa.br/ digital/bitstream/item/50057/1/DOC266-10.pdf>. Acesso em: 20 ago. 2016.

KIEHL, E.J. Manual de compostagem: maturação e qualidade do composto. 4. ed. E. J. Kiehl. Piracicaba. 173 p, 2004.

KUCZENSKI, B.; GEYER, R.; ZINK, T.; HENDERSON, A. Material flow analysis of lubricatingoil use in California. Resources, Conservation and Recycling, v. 93, p. 5966, dez. 2014. Disponível em: <http:/ / www.sciencedirect.com/science/article/pii/ S0921344914002067 >. Acesso em: 28 de agosto de 2016.

MASON, I. G.; MILKE, M. W. Physical modelig of the compostng environment: A review. Part 1: Reactor systems. Waste Management, v. 25, n. 5, p. 481-500, 2005.

MATILAINEN, A.; GJESSING, E.; LAHTINEN, T.; HED, L.; BHATNAGAR, A.; SILLANPÄ̈̈, M. An overview of the methods used in the characterization of natural organic matter (NOM) in relation to drinking water treatment. Chemosphere, v. 83, p. $1431-1442,2011$. 
NADOLNY, H. S. Reprodução e desenvolvimento das minhocas (Eisenia andrei) Bouché 1972 e Eudrilus eugeniae (Kinberg 1867) em resíduo orgânico doméstico. Curitiba, PR. 2009.

NETTO, A. D. P.; DIAS, J. C. M.; ARBILLA, G.; OLIVEIRA, L. F.; BAREK, J. Avaliação da contaminação humana por Hidrocarbonetos Policíclicos Aromáticos e seus derivados nitratos: Uma revisão metodológica, Química Nova, v. 23, n. 6, p. 765-773, 2000 .

NOVOTNY, E. H. et al. Effect of residual vanadyl on the spectroscopic analysis of humic acids. Organic Geochemistry, v. 37, n. 11, p. 1562-1572, 2006.

PIMENTA, A.S.; SANTANA, J.A.S.; ANJOS, R.M.; BENITES, V.M.; ARAÚJO, S.O. Caracterização de ácidos húmicos produzidos a partir de carvão vegetal de duas espécies florestais do semi-árido: Jurema preta (Mimosa tenuiflora) e Pereiro (Aspidosperma pyrifolium). Revista Verde de Agroecologia e Desenvolvimento Sustentável, v.4, n.4, p. 01-11, 2009.

POTIN et al. Bioremediation of an aged polycylic aromatic hydrocarbons (PAHs)contaminated soil by filamentous fungi isolated from the soil. International

Biodeterioration and Biodegradation, Oxford, v. 54, n. 1, p. 45-52, 2004.

RAVIV, M.; MEDINA, S.; KRASNOVSKY, A. \& ZIADNA, H. Organic matter and nitrogen conservation in manure compost for organic agriculture. Compost Sci. Util., 12:6-10, 2004.

RICE, J. Humim. Soil Science, 166:848-857, 2001.

RODRIGUES, M.S.; F.C. DA. SILVA, L.P. BARREIRA E A. KOVACS. Compostagem: reciclagem de resíduos sólidos orgânicos. In: Spadotto, C.A.; Ribeiro, W. Gestão de Resíduos na agricultura e agroindústria. FEPAF. Botucatu. p. 63-94, 2006.

SCHIEDECK, G. Espécies de minhocas para minhocultura. 2010. Disponível em: <http://www.infobibos. com/Artigos/2010_4/minhocultura/index.htm>. Acesso em: 10 ago. 2016.

SCHIEDECK, G.; GONÇALVES, M. M.; SCHWENGBER, J. E. Minhocultura e produção de húmus para a agricultura familiar. Embrapa/ Circular técnica 57. Pelotas, RS 2006.

SHIPITALO, M. J. \& R.-C. BAYON. Quantifying the effects of earthworms on soil aggregation and porosity. Pp. 183-200. In: C.A. Edwards (Ed.). Earthworm ecology. 2. ed. CRC Press, Boca Raton, 2004.

SHU, Y. Y.; LAI, T. L.; LIN, H. S; YANG, T. C.; CHANG, C. P. Study of factors affecting the extraction efficiency of polycyclic aromatic hydrocarbons from soils using open-vessel focused microwave-assisted extraction. Chemosphere, Oxford, $\mathrm{v}$. 52, p. 1667-1676, 2003. 
SILVA, I.R.; MENDONÇA, E.S. Matéria orgânica do solo. In: NOVAIS, R.F.;

ALVAREZ, V.H.; BARROS, N.F.; FONTES, R.L.F.F.; CANTARUTTI, R.B.; NEVES, J.

C.L. Fertilidade do solo. Viçosa: SBCS, 2007.

SILVA, M. A., RIBEIRO, S. N., CRISPIM, D. L., SOBRINHO, L. G. A; FARIAS, C. A. S. Avaliação do gerenciamento de resíduos de óleos lubrificantes e suas embalagens em oficinas mecânicas da cidade de Pombal - PB, Brasil. Revista Verde de Agroecologia e Desenvolvimento Sustentável, Pombal, v. 9, n. 4, p. 53-58, out-dez. 2014. Disponível em: <http:/ / www.gvaa.com.br/revista/index.php/RVADS/article/viewFile/3004/ pdf_1073>. Acesso em: 27 de agosto 2016.

SILVEIRA, E. L. C.; CALAND, L. B.; MOURA, C. V. R. Determinação de contaminantes em óleos lubrificantes usados em esgotos contaminados por esses lubrificantes. Química Nova, v. 29, p. 1193-1197, 2006.

TEIXEIRA, L.B. et al. Processo de compostagem, a partir de lixo orgânico urbano, em leira estática com ventilação natural. Belém: Embrapa, 8 p, 2004.

TIQUIA, S.M. \& TAM, N.F.Y. Fate of nitrogen during composting of chicken litter. Environ. Poll, n. 110, p. 535-541, 2000.

VALENCIA, S.; MARÍN, J. M.; RESTREPO, G.; FRIMMEL, F.H. Application of excitation - emission fluorescence matrices and UV/Vis absorption to monitoring the photocatalytic degradation of commercial humic acid. Science of the Total Environment, n. 442, p. 207 - 214, 2013.

VICENTINI, L.S. Utilização de microrganismos eficazes no preparo da compostagem. Revista Brasileira de Agroecologia, v. 4, n.2, 2009. 